\title{
Complementary methods to plan pedestrian evacuation of the French Riviera's beaches in case of tsunami threat: graph- and multi-agent-based modelling
}

\author{
A. Sahal ${ }^{1}$, F. Leone ${ }^{2}$, and M. Péroche ${ }^{2}$ \\ ${ }^{1}$ UMR LGP (8591), Université Paris 1 Panthéon-Sorbonne, 1 place A. Briand, 92195, Meudon, France \\ ${ }^{2}$ UMR GRED (0007), Université Montpellier 3 \& IRD, Centre IRD, 34394 Montpellier, France \\ Correspondence to: A. Sahal (alexandre@sahal.fr) \\ Received: 13 December 2012 - Published in Nat. Hazards Earth Syst. Sci. Discuss.: - \\ Revised: 15 May 2013 - Accepted: 16 May 2013 - Published: 4 July 2013
}

\begin{abstract}
Small amplitude tsunamis have impacted the French Mediterranean shore (French Riviera) in the past centuries. Some caused casualties; others only generated economic losses. While the North Atlantic and Mediterranean tsunami warning system is being tested and is almost operational, no awareness and preparedness measure is being implemented at a local scale. Evacuation is to be considered along the French Riviera, but no plan exists within communities. We show that various approaches can provide local stakeholders with evacuation capacities assessments to develop adapted evacuation plans through the case study of the Cannes-Antibes region. The complementarity between large- and small-scale approaches is demonstrated with the use of macro-simulators (graph-based) and micro-simulators (multi-agent-based) to select shelter points and choose evacuation routes for pedestrians located on the beach. The first one allows automatically selecting shelter points and measuring and mapping their accessibility. The second one shows potential congestion issues during pedestrian evacuations, and provides leads for the improvement of urban environment. Temporal accessibility to shelters is compared to potential local and distal tsunami travel times, showing a $40 \mathrm{~min}$ deficit for an adequate crisis management in the first scenario, and a 30 min surplus for the second one.
\end{abstract}

\section{Introduction}

Historically, tsunamis have impacted the French Riviera. Identified historical run-ups reached $3.5 \mathrm{~m}$ in Antibes in 1979, when a landslide-triggered tsunami impacted this area, killing a few people (Sahal and Lemahieu, 2011; Assier-Rzadkiewicz et al., 2000). More recently, in 2003 the Boumerdès-Zemmouri earthquake generated a tsunami that impacted several harbours of this area at night, generating important economic loss (Sahal et al., 2009). This area of the Mediterranean Sea is exposed to tsunamis triggered by earthquakes from the North African faults (Sahal et al., 2009), by submarine landslides (Papadopoulos et al., 2007) and local coastal landslides (Sahal and Lemahieu, 2011; AssierRzadkiewicz et al., 2000). Historical hazard studies show a rather low tsunami hazard in this area, but high vulnerability due to the lack of awareness and preparedness and to the high urban density and attendance (Robert et al., 2011). Nowadays, civil defence services are looking for operational solutions to prepare evacuations in case of alert during high attendance periods (July-August), which are considered as the most problematic scenarios of human exposure.

Several steps are necessary to build evacuation plans: assessing the exposure to the hazard, quantifying the exposed population, identifying possible shelter areas and evacuation routes, and, finally, selecting some of them based on their accessibility. A complementary step consists in optimizing the urban environment design for such an evacuation. The aim of this paper is to propose two complementary methods to identify and select shelter areas and evacuation routes, and to enhance urban management to facilitate potential evacuations. 

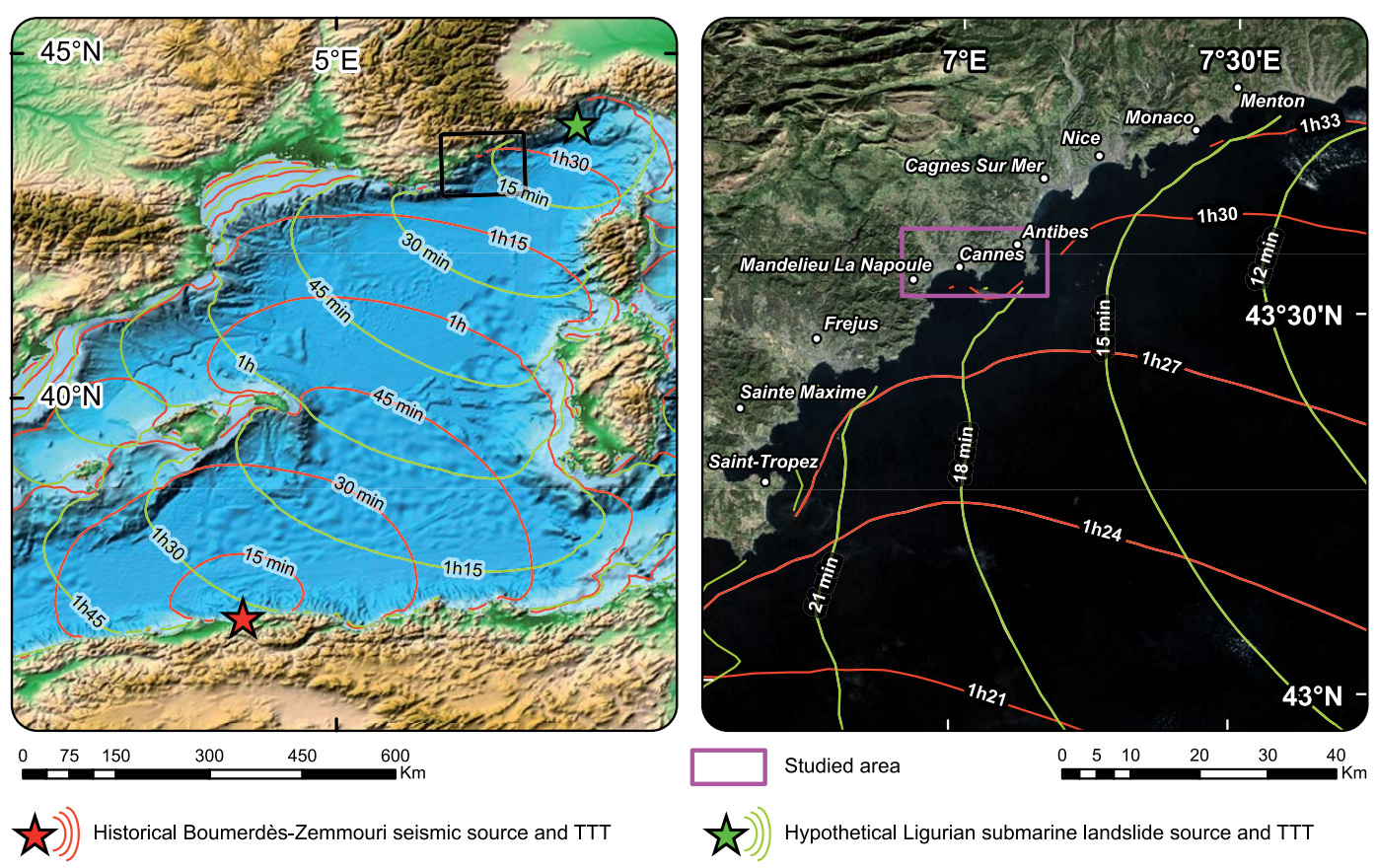

Fig. 1. Tsunami travel times (TTTs) for both hazard scenarios and location of the area studied for evacuation.

Theoretical evacuation times are modelled, based on the shortest routes, and confronted with hypothetic hazard scenarios such as the following: (1) the fault-triggered tsunami of Boumerdès-Zemmouri (Sahal et al., 2009), as described by Delouis et al. (2004), located at $36.83^{\circ} \mathrm{N}, 3.65^{\circ} \mathrm{E}$; and (2) a potential regional source of landslide-triggered tsunami in the Ligurian Sea located at $44^{\circ} \mathrm{N}, 8.5^{\circ} \mathrm{E}$. Tsunami travel times are computed using the TsuDIG software with a 2 arcminute bathymetric grid (Fig. 1). The computation shows travel times of $1 \mathrm{~h} 30 \mathrm{~min}$ for the first scenario and of $18 \mathrm{~min}$ for the second one.

\section{Methods}

Pidd et al. (1996) distinguish two main approaches to model and simulate evacuations: (1) macro-simulators compute travel times in open areas or networks, describing each portion of space by attributes that pressure the velocity of pedestrians, enabling simulations on a large scale; (2) microsimulators try to simulate the loss of velocity generated by the interactions between pedestrians (Helbing and Molnár, 1995) on the individual scale. The first approach is used here to choose evacuation routes on a large scale (from Mandelieu to Antibes, Fig. 2) while the second one is used to highlight congestion issues due to the street furniture and suggests simple environmental enhancement. This study is conducted on a smaller area, on a local scale, i.e. the neighbourhood of $\mathrm{La}$ Salis beach, the most impacted area during the 1979 event (Sahal and Lemahieu, 2011), located in Fig. 2.
Only beaches are considered as source areas for pedestrian evacuations and are digitalized as surfaces of equal human density based on previous human attendance studies during the summer (Robert, 2011; Sahal et al., 2011; Robert et al., 2011), with the objective of providing time-based accessibility curves to shelter areas. The beaches of the studied area totalize a surface of $223248 \mathrm{~m}^{2}$, hypothetically gathering slightly fewer than 38000 people for a peak attendance scenario, corresponding to an homogenous density of 0.17 persons per square metre ( 1 for $5.9 \mathrm{~m}^{2}$ ). People from urban areas are neglected at this preliminary stage, as beaches represent the densest and most exposed areas with a high human vulnerability.

\subsection{A graph-theory and network-based macro-simulator: RouteFinder ${ }^{\odot}$}

Once people at stake on beaches are quantified, the RouteFinder $^{\circledR}$ approach consists in (1) identifying potential shelter areas, (2) mapping accesses to the beaches and quantifying the people depending on them, (3) identifying the most accessible shelter areas following the shortest evacuation routes, and finally, (4) quantifying the access time and number of people depending on each shelter area.

RouteFinder $^{\circledR}$ software (http://www.routeware.dk) is based on Euler's graph theory (Deo, 2004) estimating the accessibility from a point of a network to another. The road and path network is represented as a graph, in which intersections are associated with nods and roads are associated with arcs. The graph has to consider the 


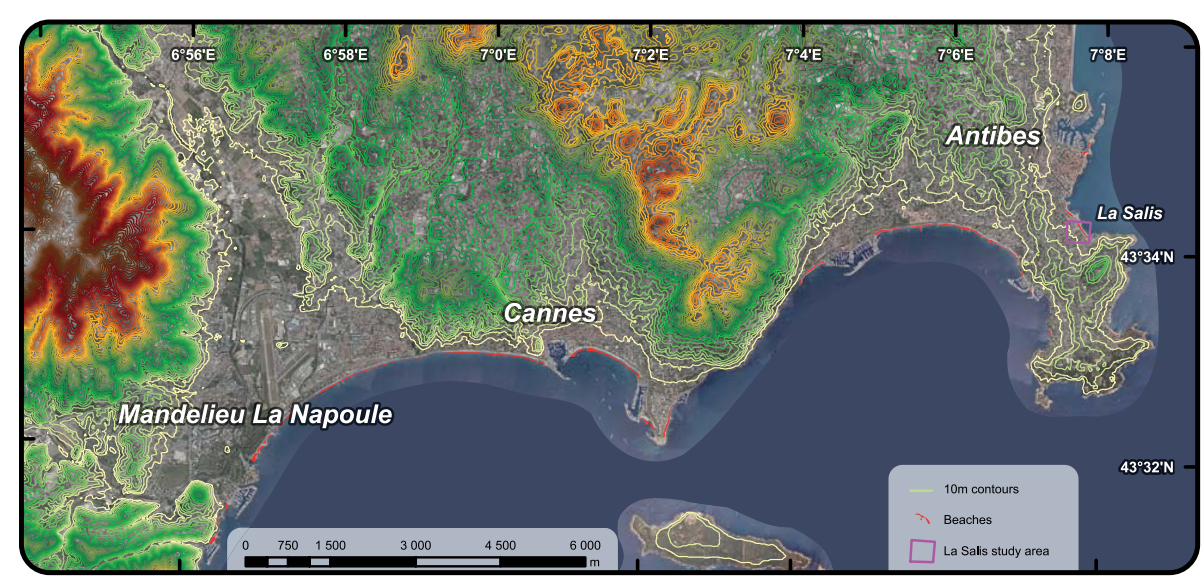

Fig. 2. Topographical context, beaches of the studied area and location of La Salis beach.

road hierarchy (Appert and Chapelon, 2006) and be valued depending on the width and slope of the road as both parameters influence pedestrians' velocity. The data used for network analysis are provided by the Institut National de l'Information Géographique et Forestière (IGN, BDTopo), updated in 2011. The digital elevation model is of a $5 \mathrm{~m}$ resolution and provided by the Centre Régional de l'Information Géographique Provences-Alpes Côte d'Azur (CRIGE PACA), and was set up in 2009. The road network is updated when inaccurate, through on-site observations (mostly along the railway line that runs along the main coastal road). Beaches are mapped through aerial imagery interpretation (IGN, BDOrtho, 2009), and access points to beaches are mapped during a field survey. As a first step, potential access points to horizontal shelters are defined by the intersection of the road network and the $20 \mathrm{~m}$ contour (Fig. 3). This elevation was chosen in absence of tsunami modelling at this large scale, but can easily be adjusted when submersion models are available. This elevation ensures total security for people in case of a tsunami.

People on beaches are distributed homogeneously to each beach access from the road network (Fig. 4). Pedestrians' velocity is considered at a "comfortable" walking velocity deduced from literature, considering the slope and width of the roads, but without taking potential congestion and interactions between individuals into consideration. Moussaïd (2010) synthesizes from literature an average speed ranging between $0.9 \mathrm{~m} \mathrm{~s}^{-1}$ and $1.5 \mathrm{~m} \mathrm{~s}^{-1}$. Daamen (2004), using 27 different sources, suggests a $1.34 \mathrm{~m} \mathrm{~s}^{-1}$ average speed. Dewi (2010) suggests a mean velocity of $0.751 \mathrm{~m} \mathrm{~s}^{-1}$ for tsunami threat evacuations, which corresponds to the velocity of a group of elderly people. By definition, tsunami threat evacuations imply a positive slope that must be considered. Bles et al. (2001), Lee et al. (2004) and Laghi et al. (2006) took this parameter into consideration, which ensued in the choice of a $30^{\circ}$ threshold, from which pedestrian evacuations are not possible. Since the congestion due to the density of pedestrians (Fruin, 1971; Polus et al., 1983; Tanaboriboon and Guyano, 1989; Paris, 2007; Shi et al., 2007; Moussaiid, 2010) is not taken into account in the model, a friction coefficient is used to value the graph, based on Dewi (2010). This synthesis was completed by standardized values frequently used for urban mobility calculus, and from velocities measured on-site. Finally, a polynomial regression of the available data ( 89 values) provides a curve linking pedestrians' velocity to the slope of the road, with a $1.39 \mathrm{~m} \mathrm{~s}^{-1}$ velocity for a flat road (Fig. 5). RouteFinder ${ }^{\odot}$ seeks the shortest paths within the graph using the algorithm of Dijkstra (1959), considering time ("fastest" mode) or distance ("shortest" mode) as available parameters.

\subsection{A multi-agent micro-simulator: SimWalk ${ }^{\odot}$}

SimWalk $^{\odot}$ was designed to assess pedestrian behaviour in normal or stressed conditions (Zainuddin et al., 2009) inside buildings. Based on a social force model (Helbing and Molnár, 1995), it makes each agent act individually according to his/her destination, environment, level of stress, and depending on the other agents' behaviour. The level of service (i.e. the space needed for each agent to walk freely at his/her optimal velocity) is configured according to the FGSV (2001). Antibes' technical services provided the spatial data used for the micro-simulation, including dense altimetry points, buildings and parcels. The available urban environment data were completed by fieldwork, which consisted in collecting and mapping objects that could potentially influence pedestrian tracks (obstacles). Detailed mapping of the studied area is conducted, showing every constraint for the movement of pedestrians, including walls, gates, telephone kiosks, benches, cars, etc. The model can simulate constrained evacuations as it suggests the use of forced checkpoints, equivalent to signposted routes or police enforcement actions (Sahal, 2011). 


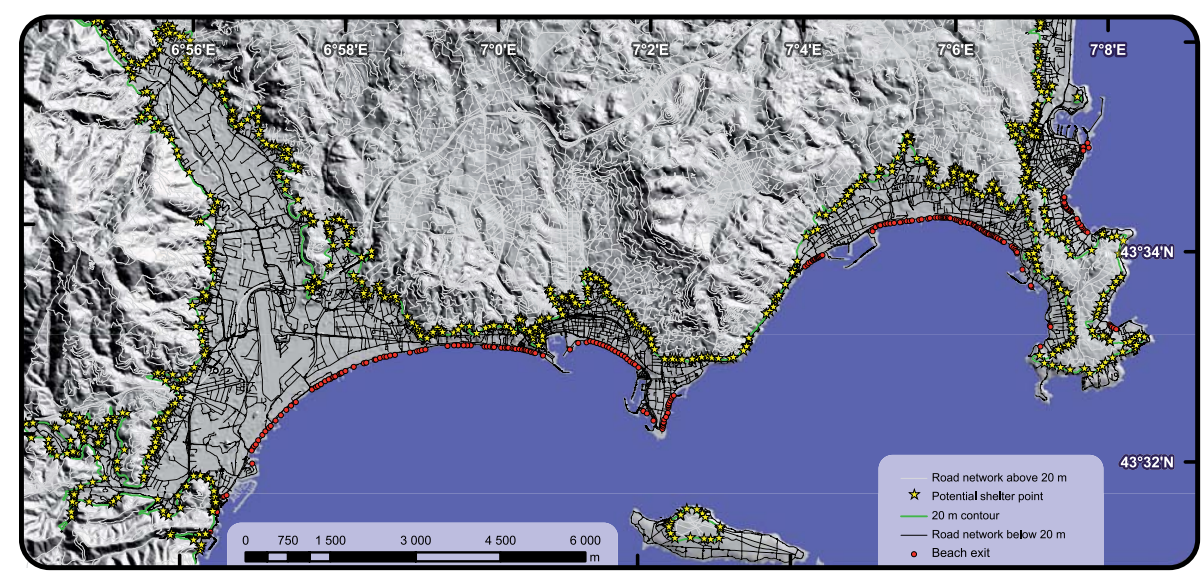

Fig. 3. Road network, potential shelter points and exits from the beaches.

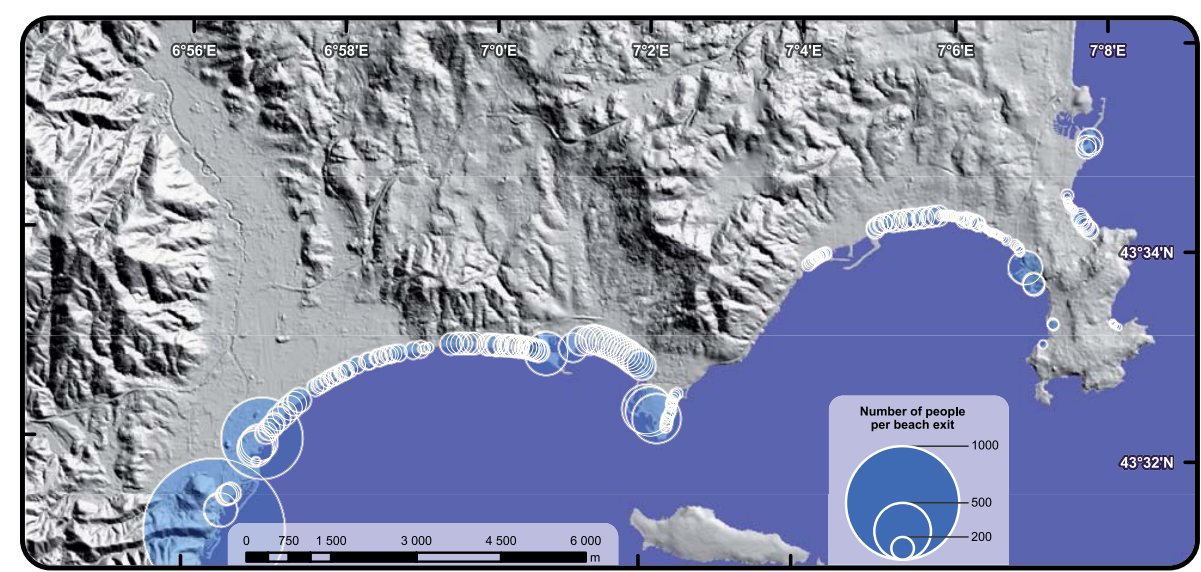

Fig. 4. People per beach exit that would need to be evacuated.

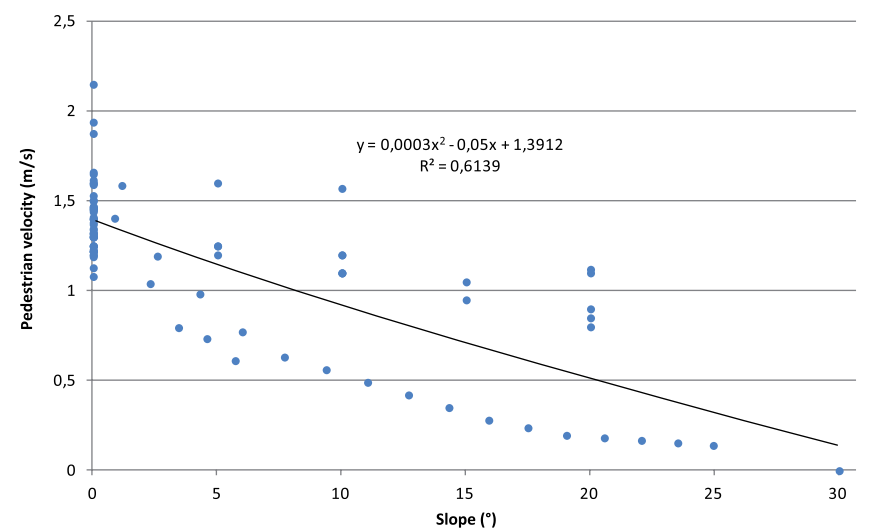

Fig. 5. Pedestrian velocity depending on the slope: bibliographic synthesis and function used.
Source and destination areas are selected, and three evacuation scenarios are offered. The first one illustrates a spontaneous evacuation: the model lets every agent choose his/her route to the shelter area, unconscious imitation rules as people who are the closest to the best route lead everyone. A second scenario adds signposted routes, dividing the flux over three main routes. A third scenario suggests an enhancement of the street furniture to optimize evacuation capacities: pedestrian crossings are implemented (removal of parked cars), and the wall along the beach is partially destroyed enabling better access from the beach to the road (Fig. 6). According to attendance studies (Robert, 2011; Sahal et al., 2011; Robert et al., 2011), the maximal measured attendance on La Salis beach reaches 1000 people in summer, which is the number of agents the simulation is set with. Each simulation is computed 3 times, as the location of each agent is random within the beaches. The shelter area is here located $12 \mathrm{~m}$ high, as the highest known submersion reached $3.5 \mathrm{~m}$ in La Salis (Sahal and Lemahieu, 2011). 

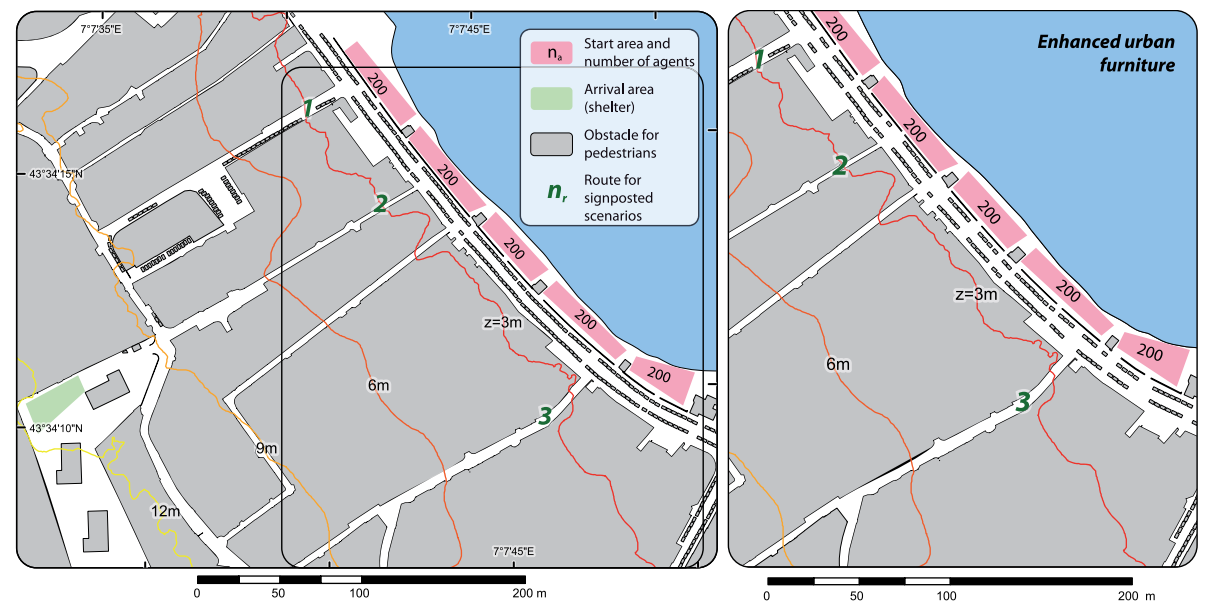

Fig. 6. Location of the sources, destination and enforced routes for pedestrians in both current and enhanced urban environment.

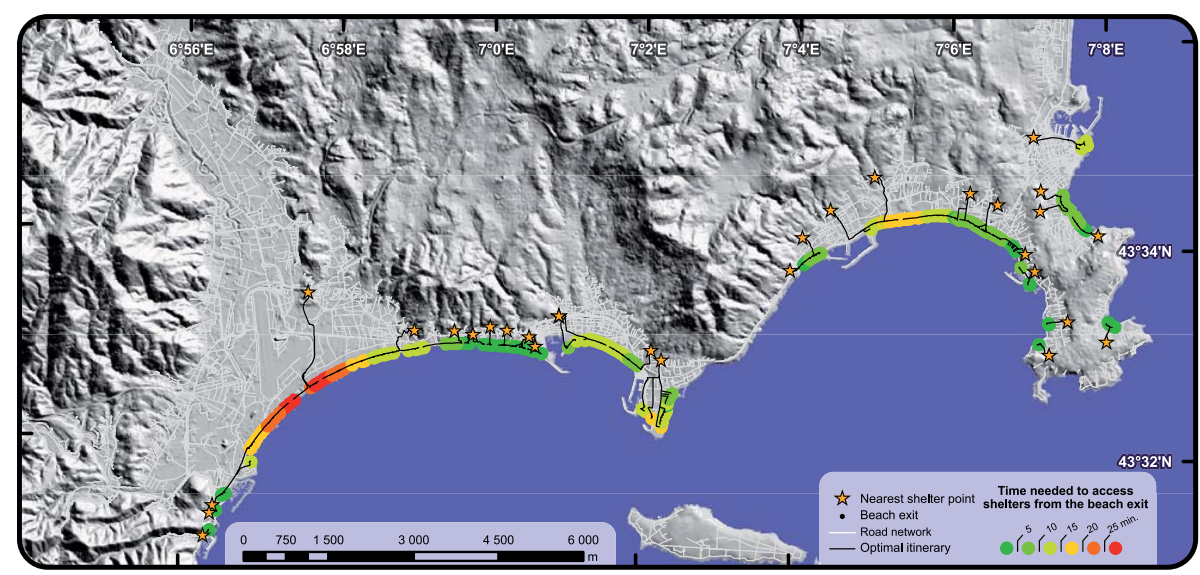

Fig. 7. Access time from beach exits to nearest shelter points.

\section{Results: quantifying accessibility on different scales}

\subsection{RouteFinder $^{\odot}$ to optimize shelter areas and evacuation routes on a global scale}

RouteFinder $^{\odot}$ enables the mapping of the nearest shelters considering walking time. It also enables the mapping of the maximal access time to each potential shelter area (Fig. 7) and potential load for shelters (Fig. 8). Out of the 801 potential access points to shelter areas, the model selects 32 (the most accessible ones). Maximal theoretical access time to shelters is over $28 \mathrm{~min}$, while maximal charges reach 4300 people for one shelter area (western part). RouteFinder ${ }^{\odot}$ also allows the mapping of the charges for roads, quantifying the number of pedestrian tracks, which provides a first assessment of potential congestion issues (Fig. 9). Finally, arrival times for both hazard scenarios are compared to the time necessary for evacuation, consider- ing an ideal early warning of $15 \mathrm{~min}$ and a population reaction time of 15 min (Post et al., 2009; Strunz et al., 2011) (Fig. 10).

Computed tsunami travel times and evacuation time show the following: (1) a $40 \mathrm{~min}$ deficit to evacuate for the Ligurian Sea tsunami scenario, implying a high exposition of people on beaches; and (2) a 32 min surplus of time for a Boumerdès-Zemmouri-type tsunami scenario, implying no exposure of people on the beach if evacuated.

\subsection{SimWalk $^{\odot}$ for the optimization of evacuation routes and street furniture}

Results from the micro-simulations show an average evacuation time of $8 \mathrm{~min}$ to reach the shelter area without enforcement and environmental changes. With enforcement, the average gain is $0.7 \mathrm{~min}$, and $1.08 \mathrm{~min}$ with enforcement and environmental enhancement (Fig. 11). An animated simulation 


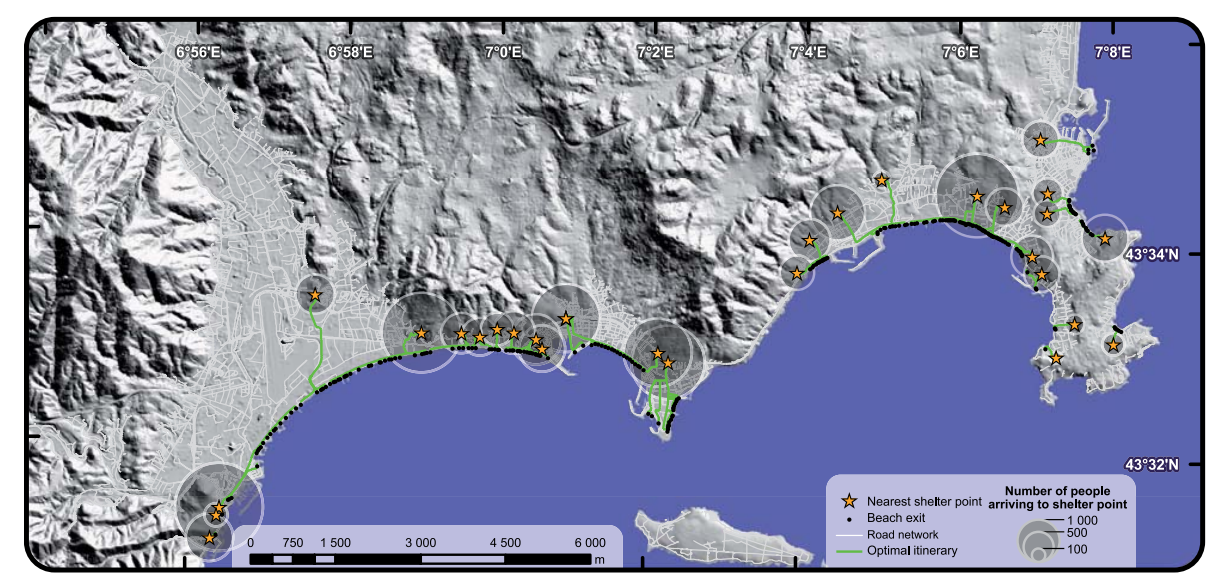

Fig. 8. Potential load for nearest shelter points.

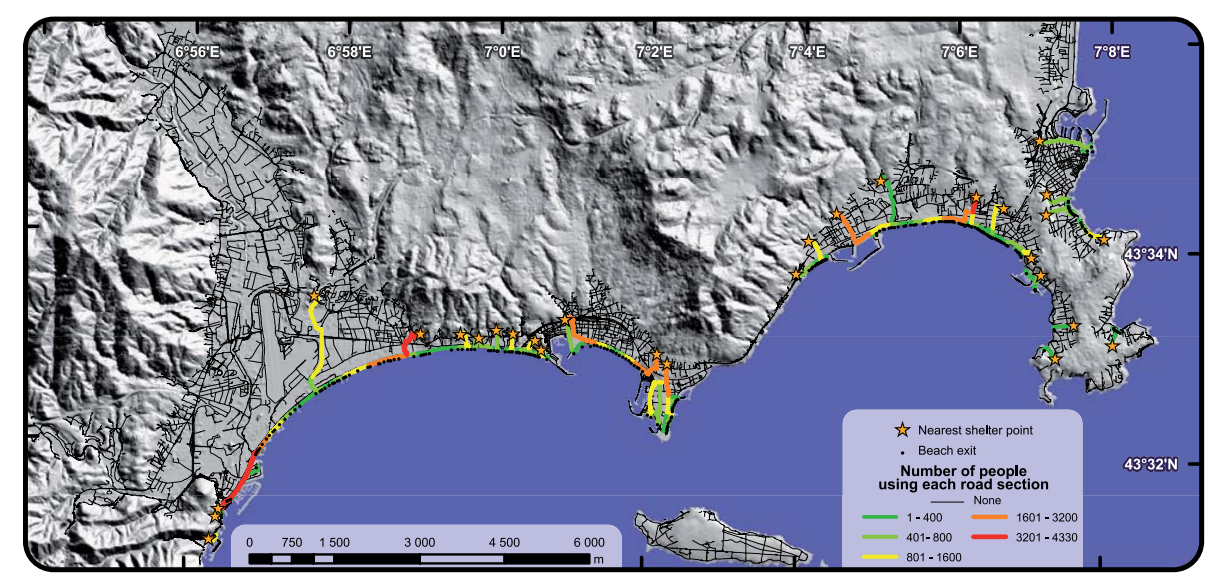

Fig. 9. Shelter entrance points and charge for evacuation routes.

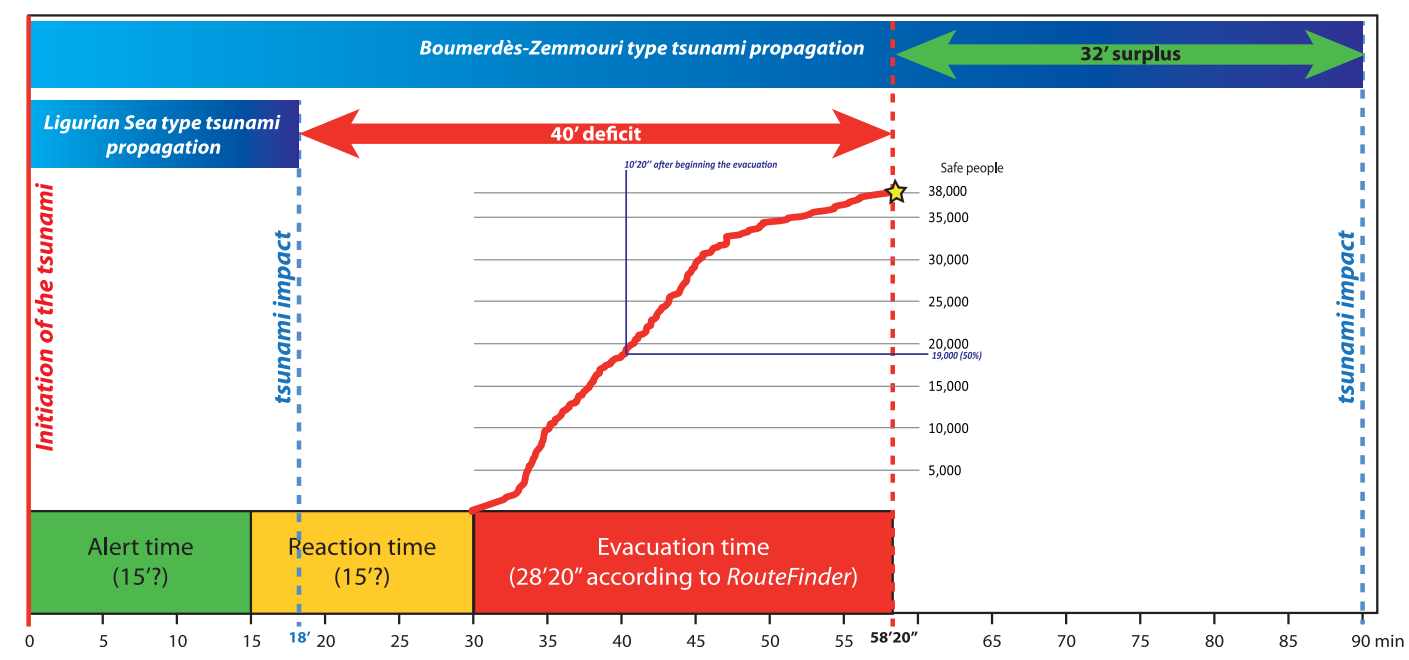

Fig. 10. Confrontation of the modelled accessibility curve for shelters vs. hazard scenarios: deficit and surplus for crisis management. 

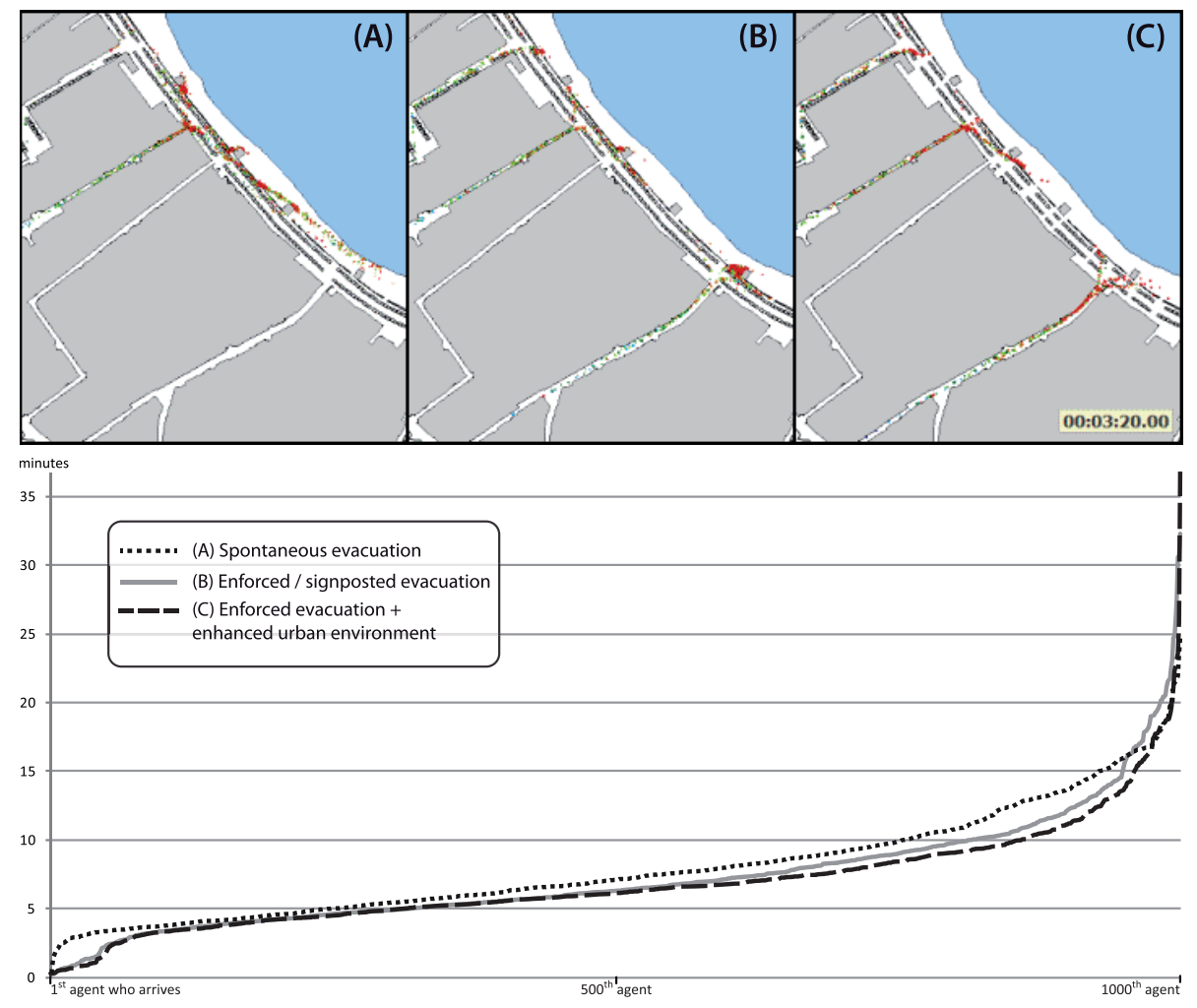

Fig. 11. Micro-simulation results for the three different scenarios and extract of the simulations after $3 \mathrm{~min}$ and $20 \mathrm{~s}$.

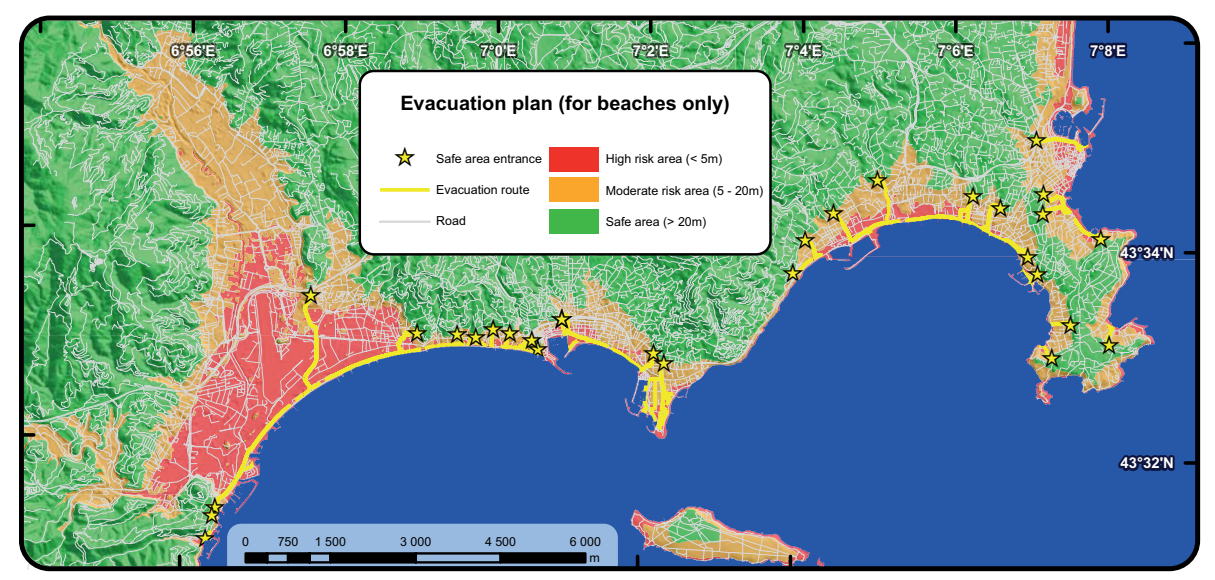

Fig. 12. Suggestion of large-scale evacuation plan.

is available at http://sahal.fr/antibes-2011/. Such a gain appears to be significant as it represents a $12.5 \%$ mean improvement of the evacuation time. The results of the first two scenarios helped to highlight places of constriction and to adapt the urban environment for the third scenario. It is worth noting that this adaptation was instinctive and that many other adaptation scenarios could have been simulated to further improve accessibility. A few agents got stuck between cars during the enforced simulations, which deteriorated the statistics for the slowest agents and reveals the software's limitations in processing complex environments (interactions with narrow paths in this case).

\section{Model comparison and discussion}

RouteFinder $^{\circledR}$ appears to be a significant tool to select potential shelter accesses on a large scale and to design evacuation plans (Fig. 12). It enabled building accessibility curves that indicate the number of evacuees through time. The execution 
of this tool is fast and efficient as soon as the graph is built. In this study, every road reaching $20 \mathrm{~m}$ contours was considered as an access point to shelter, but the validity of such shelter areas would need a proper field-based selection considering their availability in case of a tsunami threat and their stocking capacities (ARC, 2002), in coordination with local authorities. The $20 \mathrm{~m}$ threshold for shelter areas is much higher than the known historical run-ups in this area and could be lowered in some areas where modelling does not show tsunami amplifications. Vertical evacuation could also be considered (FEMA, 2008) to enhance shelter accessibility, especially within areas that are far from higher ground.

The SimWalk ${ }^{\odot}$ micro-simulator showed great potential for street furniture improvement within the framework of tsunami hazard evacuations. It was designed for indoor evacuations but seems promising in outdoor contexts. The time necessary for the slowest agents to reach the shelter shows important peaks. The observation of these agents' behaviour showed an increase of the number of people blocked between obstacles (i.e. cars) as the environment (and simulation) became more complex, which is a limiting factor for this micro-simulator. After 100 iterations, the simulator unlocks the position of the blocked agent. This number of iterations may need to be reduced to prevent the simulation from this bias.

Both models show a great synergy for the multi-scale approach required for a proper optimization of evacuation routes. Nevertheless, they both assume evacuees' rational behaviour and their perfect knowledge of the shortest path to shelters.

\section{Conclusions}

This study showed the important exposure of people in case of a flooding tsunami of local or regional origins along the French Mediterranean coast. Only distal tsunami sources such as those from the North African margin could leave enough time to evacuate the numerous people at stake considering the chosen alert and reaction times.

Both simulations showed how the selection of relevant evacuation routes, as well as appropriate urban planning, could facilitate an evacuation. These simulators appear as key tools to plan evacuations of urban coastal areas adequately and could be of great interest for stakeholders and decision makers. These simulations were conducted considering the evacuees' rational behaviour. In the real world, evacuations would need adapted awareness and preparedness, including the identification of credible shelter areas and the selection and display of evacuation routes (IOC/UNESCO, 2011). Real evacuation would require proper enforcement to guide and reassure evacuees, preventing stampedes and their disastrous consequences.
Acknowledgements. This study was conducted within the RiskNat programme under contract ANR-08-RISKNAT-00501/MAREMOTI. The authors would like to thank the local authorities for their technical support, and Marion Cole for reviewing the English of this article.

Edited by: M. Gonzalez Rodríguez

Reviewed by: two anonymous referees

\section{References}

Appert, M. and Chapelon, L.: La vulnérabilité des réseaux routiers urbains face aux risques d'altération, in: La mise en carte des risques naturels, Géorisque, collection du laboratoire GESTER, Université Montpellier 3, 2, 47-58, 2006.

ARC: Standards for hurricane evacuation shelter selection, American Red Cross, Tallahassee, Florida, USA, 5, 2002.

Assier-Rzadkiewicz, S., Heinrich, P., Sabatier, P. C., Savoye, B., and Bourillet, J. F.: Numerical modelling of a landslide-generated tsunami: The 1979 Nice event, Pure Appl. Geophys., 157, 17071727, 2000.

Bles, W., Nooy, S., and Boer, L. C.: Influence of ship listing and ship motion on walking speed, Conference Proceedings on Pedestrian and Evacuation Dynamics, 437-452, 2001.

Daamen, W.: Modeling passenger flows in public transport facilities, Delft University of Technology, 403 pp., 2004.

Delouis, B., Vallée, M., Meghraoui, M., Calais, E., Maouche, S., Lammali, K., Mahsas, A., Briole, P., Benhamouda, F., and Yelles, K.: Slip distribution of the 2003 Boumerdes-Zemmouri earthquake, Algeria, from teleseismic, gps, and coastal uplift data, Geophys. Res. Lett., 31, L18607, doi:10.1029/2004GL020687, 2004.

Deo, N.: Graph theory with applications to engineering and computer science, Prentice-Hall of India Pvt.Ltd, 496 pp., 2004.

Dewi, R. S.: A GIS-based approach to the selection of evacuation shelter buildings and routes for tsunami risk reduction, Master of Sciences, Faculty of Geo-Information and Earth Observation, Gadjah Mada University, 2010.

Dijkstra, E. W.: A note on two problems in connexion with graphs, Numerische Mathematik, 1, 269-271, doi:10.1007/bf01386390, 1959.

FEMA: Guidelines for design of structures for vertical evacuation from tsunamis, FEMA P646 ed., FEMA/NOAA, Redwood City, CA, USA, 176 pp., 2008.

FGSV: Handbuch für die Bemessung von Straßenverkehrsanlagen, Forschungsgesellschaft für Straßen und Verkehrswesen, Kommission KV 6 Bemessung von Straßenverkehrsanlagen, 11.1311.28, 2001 (in German).

Fruin, J.: Pedestrian planning and design, Metropolitan Association of Urban Design and Environmental Planners, Inc., New York, USA, 1971.

Helbing, D. and Molnár, P.: Social force model for pedestrian dynamics, Phys. Rev. E, 51, 4282-4286, doi:10.1103/PhysRevE.51.4282, 1995.

IOC/UNESCO: Reducing and managing the risk of tsunamis, IOC Manuals and Guides, Paris, France, 57, 74 pp., 2011. 
Laghi, M., Cavalletti, A., and Polo, P.: Evacuation routes tools Arcgis ${ }^{\circledR}$ toolbox, user's manual, Asian Disaster Preparedness Center, Italian Ministry for the Environment and Territory, Bangkok, Thailand, 98 pp., 2006.

Lee, D., Park, J.-H., and Kim, H.: A study on experiment of human behavior for evacuation simulation, Ocean Eng., 31, 931-941, 2004.

Moussaïd, M.: Étude expérimentale et modélisation des déplacements collectifs de piétons, Ph.D. thesis, Université de Toulouse III, Toulouse, France, 225 pp., 2010.

Papadopoulos, G. A., Daskalaki, E., and Fokaefs, A.: Tsunamis generated by coastal and submarine landslides in the Mediterranean Sea, in: Submarine mass movements and their consequences, edited by: Lykousis, V., Sakellariou, D., and Locat, J., 415-422, 2007.

Paris, S.: Caractérisation des niveaux de services et modélisation des circulations de personnes dans les lieux d'échanges, Ph.D. thesis, Université de Rennes, France, 1, 308 pp., 2007 (in French).

Pidd, M., de Silva, F. N., and Eglese, R. W.: A simulation model for emergency evacuation, European J. Operational Res., 90, 413419, 1996.

Polus, A., Schofer, J. L., and Ushpiz, A.: Pedestrian flow and level of service, J. Transp. Eng.-ASCE, 109, 46-56, 1983.

Post, J., Wegscheider, S., Mück, M., Zosseder, K., Kiefl, R., Steinmetz, T., and Strunz, G.: Assessment of human immediate response capability related to tsunami threats in Indonesia at a sub-national scale, Nat. Hazards Earth Syst. Sci., 9, 1075-1086, doi:10.5194/nhess-9-1075-2009, 2009.

Robert, C.: Elaboration d'une méthodologie pour l'étude de fréquentation d'une zone à forte vulnérabilité humaine, Laboratoire de Géographie Physique, UMR 8591, Université Paris 1 Panthéon-Sorbonne, Paris, France, 96 pp., 2011.

Robert, C., Sahal, A., and Lavigne, F.: Assessing human vulnerability to tsunami hazard in the Western Mediterranean, UGI Regional Geographic Conference, Santiago, Chile, 2011.
Sahal, A., Roger, J., Allgeyer, S., Lemaire, B., Hébert, H., Schindelé, F., and Lavigne, F.: The tsunami triggered by the 21 May 2003 Boumerdès-Zemmouri (Algeria) earthquake: field investigations on the French Mediterranean coast and tsunami modelling, Nat. Hazards Earth Syst. Sci., 9, 1823-1834, doi:10.5194/nhess-9-1823-2009, 2009.

Sahal, A.: Le risque tsunami en France: Contributions méthodologiques pour une évaluation intégrée par scénarios de risque, Ph.D. thesis, Laboratoire de Géographie Physique UMR 8591, Université Paris 1 Panthéon-Sorbonne, Paris, France, 268 pp., 2011 (in French).

Sahal, A. and Lemahieu, A.: The 1979 Nice airport tsunami: Mapping of the flood in Antibes, Nat. Hazards, 56, 833-840, doi:10.1007/s11069-010-9594-6, 2011.

Sahal, A., Lavigne, F., and Robert, C.: Apports de la modélisation multi-agents pour la planification d'évacuations de plages en cas de risque tsunami: Étude du cas de la plage de la Salis, Villes, risques majeurs et évacuations, Compiègne, France, 2011.

Shi, J., Chen, Y., Rong, and Ren, F.: Research on pedestrian crowd characteristics and behaviours in peak-time on chinese campus, in: Pedestrian and Evacuation Dynamics 2005, edited by: Waldau, N., Gattermann, P., Knoflacher, H., and Schreckenberg, M., Springer Berlin Heidelberg, Berlin, Heidelberg, Chapter 7, 7990, 2007.

Strunz, G., Post, J., Zosseder, K., Wegscheider, S., Mück, M., Riedlinger, T., Mehl, H., Dech, S., Birkmann, J., Gebert, N., Harjono, H., Anwar, H. Z., Sumaryono, Khomarudin, R. M., and Muhari, A.: Tsunami risk assessment in Indonesia, Nat. Hazards Earth Syst. Sci., 11, 67-82, doi:10.5194/nhess-11-67-2011, 2011.

Tanaboriboon, Y. and Guyano, J. A.: Level of service standards for pedestrian facilities in bangkok: A case study, ITE Journal, 59, 39-41, 1989.

Zainuddin, Z., Thinakaran, K., and Abu-Sulyman, I. M.: Simulating the circumambulation of the ka'aba using simwalk, Euro. J. Scientific Res., 38, 454-464, 2009. 